\title{
The Solving Method of Residential Engineering Quality Based on Evidence-Science
}

\author{
Xue-liang HOU ${ }^{a}$, Yi WANG \\ Institute of engineering management, North China electric power university, Beijing, China \\ ahou-x|@163.com, bwangyikelven@163.com
}

\begin{abstract}
Keywords: Residence Engineering, Quality, Solving Method, Evidence-science.
Abstract. In order to solve residential engineering quality problems, the concept of evidence-science and its management principle is analyzed. Under the guidance of the evidence-science, the program to solve residential engineering quality based on evidence-science principle is put forward together with the characteristics of residential engineering, and the corresponding flow chart of the program is offered. Finally, the validity of this solving method has been proved by a real engineering experiment. The experimental data shows that the evidence-science management method can not only ensure the implement quality of every working procedure to meets predetermined requirement, but also eliminate the cumulative effect formed by deviation of every procedure to final engineering quality.
\end{abstract}

\section{Introduction}

With the rapid development of Chinese economy in recent years, people's residential condition and life environment has been changed and improved in big extend. Because the residential qualities related to people's daily life, safety and value of property, people pay more attention to house quality. However, it can be known from some mediums and related research reports that the residential quality situations in china are not so good ${ }^{[1]}$. Some residential engineering accidents appear in some cities, and house consumers' complaints also increase rapidly. The problem not only brings much adverse effect on social stability, but also produces a large amount of economic loss to nation. Thus, how to effectively solve the problem just becomes an important question in the field of engineering management.

\section{Evidence-science and its Management Principle}

Evidence-science is a kind of management theory based on actual data of management object, which is advocated in the management science field at present. The connotation of evidence-science is that after managers determine management objects and theirs target, managers should firstly carry on instant analysis of specific characteristics and related data of management object problems, and then put forward corresponding specific solutions. Meanwhile, the specific solutions should be adjusted and corrected under the condition of constantly understanding and grasping the latest management object states in order to achieve the best management effect and realize the ultimate goal of the management objects ${ }^{[2]}$.

When treating with special problems, the evidence science principle points out that if managers want to effectively control management objects, and eliminate adverse effect to management objects from all kinds of factors in the their implement process, each of management object constituent should be broken up into special minimum units, and ensure these units' corresponding management standards ${ }^{[3]}$. At the same time, the implement states of these units should be measurable, and relative data which describe their states in construction can be obtained. Thus, managers can find the deviations between real situation and standards as early as possible, and make effective and correct decisions for solving problems timely. Another most important demand is that after the result to deal with problems or deviations must meet predesigned requirements and cannot produce adverse effect to realization of ultimate goal of management objects, the next work can be permitted to carry out ${ }^{[4]}$. 
So, it can be known from the evidence science principle that the following four conditions must be possessed before using the evidence-science method.

(1) Management objects and their ultimate goals should be defined in advance.

(2) Management object constituent should be broken up into special minimum units.

(3) Each unit has its corresponding standard.

(4) The unit state can be measured.

\section{The Program to Solve Residential Engineering Quality Based on Evidence-Science}

In generally, engineering is composed of multiple sub-engineering projects, the sub-engineering project also consists of many engineering items, and every item can be realized by working procedure. In engineering, the working procedure is the most basic work unit, and has corresponding implement methods and predesigned quality inspection standard ${ }^{[5]}$. The implement state of working procedure is also measurable, so, it is possible to use evidence-science method for managing and controlling residential engineering quality.

According to the evidence-science principle, the first thing to solve the residential engineering quality problems by evidence-science method is making a whole residential engineering break up into several sub-engineering projects, and many items as well as special working procedures. Knowing from architecture and civil engineering profession, the residential engineering can be divided into such sub-engineering projects as foundation engineering, structural engineering, decoration engineering, heating and ventilation engineering, water supply and drainage engineering, electrical engineering, communication and network engineering, fireproof engineering, and auxiliary facilities $^{[6]}$. These sub-engineering projects include their relative items. For example, the roof engineering in structural engineering contains structure layer, leveling layer, gas-proofed layer, insulating layer, adjoining layer and waterproof layer. In engineering practice, these works can be completed by special procedures, and every procedure has its particular operational program and inspection standard. Thus, the program to solve residential engineering quality based on evidence-science can be given as follow after breaking up residential engineering into items. The corresponding flow chart of the program is shown in figure 1.

(1) Determine the quality control objects and their special working procedures.

(2) Ensure inspection point of every special working procedure and judgment standard.

(3) Make a construction plan in advance, and organize the construction according to the plan.

(4) Collect quality data of working procedure timely, and analyze it together with standard.

(5) Judge whether the implement result is up to the target. If yes, do next work.

(6) If there are any problems, analyze whether the problems produce influence on engineering quality, treat them in time and eliminate the cumulative effects to ultimate goal.

(7)Analyze whether the final treating result meets predesigned requirement. If yes, the next work will be carried out. Otherwise, continue to analyze and solving problems until meeting requirements.

\section{Real Example Analysis}

In many quality problems of residential construction, the rain percolation in roof is always a primal problem; the complaint from householders has a large proportion in all various residential engineering quality events. Therefore, how to ensure the roof waterproof engineering quality just becomes an important controlling object in engineering project management in recent years. In order to test the validity of the method to solve residential engineering quality based on evidence-science, a real experiment has been made in a residential engineering which includes twenty- one buildings with the support of company. The experiment has been divided in tow groups; the first group consists of buildings from one to five, which are managed by the evidence-science method. The second group is composed of buildings from six to ten, which are operated by traditional method. After four months of experiment, the following experimental data in table 1 and table 2 had been obtained, where, the 
experimental data in table 1 is the outcome by evidence -science method, and the experimental data in table 2 comes from traditional method. All number units in table are millimeter.

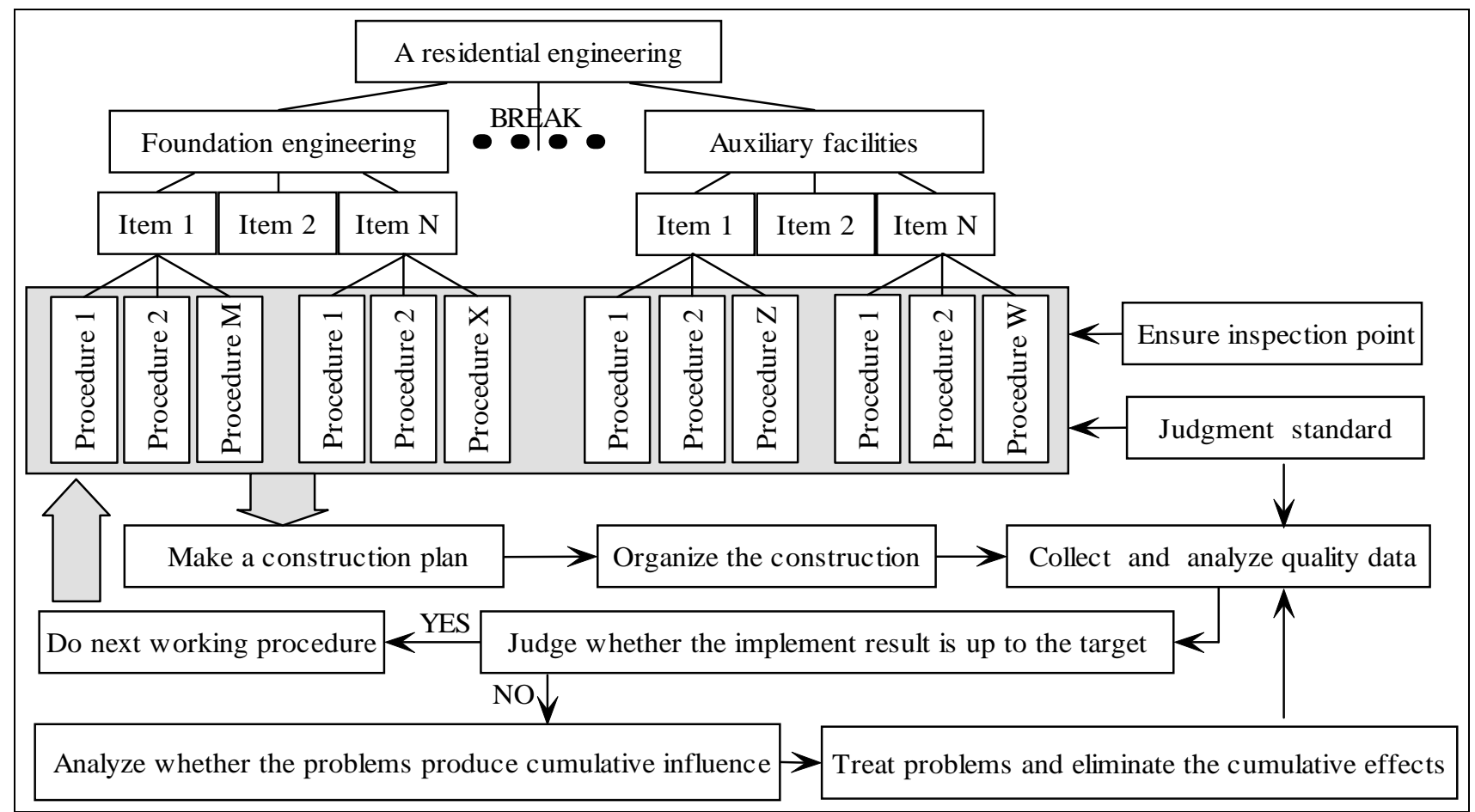

Figure 1. The flow chart to solve residential engineering quality

Table 1. The experimental data by evidence -science method

\begin{tabular}{|l|c|c|c|c|c|c|c|c|}
\hline Parameter & $\begin{array}{c}\text { Gas-proofed } \\
\text { layer }\end{array}$ & $\begin{array}{c}\text { Insulation } \\
\text { layer(First) }\end{array}$ & $\begin{array}{c}\text { Insulation } \\
\text { layer(Revise) }\end{array}$ & $\begin{array}{c}\text { Leveling } \\
\text { layer(First) }\end{array}$ & $\begin{array}{c}\text { Leveling } \\
\text { layer(Revise) }\end{array}$ & $\begin{array}{c}\text { Adjoining } \\
\text { layer }\end{array}$ & $\begin{array}{c}\text { Waterproo } \\
\text { f layer }\end{array}$ & $\begin{array}{c}\text { Cumulative } \\
\text { deviation }\end{array}$ \\
\hline Building1 & 18 & 241 & 230 & 26 & 27 & 12 & 24 & 6 \\
\hline Building2 & 15 & 236 & 228 & 20 & 28 & 13 & 23 & 6 \\
\hline Building3 & 16 & 234 & 232 & 20 & 26 & 15 & 20 & 4 \\
\hline Building4 & 14 & 238 & 226 & 20 & 29 & 13 & 21 & -2 \\
\hline Building5 & 17 & 241 & 224 & 19 & 30 & 12 & 22 & 0 \\
\hline Average value & 16 & 238 & 228 & 21 & 28 & 13 & 22 & $/$ \\
\hline Standard & 15 & 230 & 230 & 25 & 25 & 15 & 20 & 0 \\
\hline Permit deviation & \pm 3 & \pm 10 & \pm 10 & \pm 5 & \pm 5 & \pm 3 & \pm 5 & \pm 10 \\
\hline Real deviation & +1 & +8 & -2 & +4 & +3 & -2 & +2 & +2 \\
\hline
\end{tabular}

Table 2. The experimental data by traditional method

\begin{tabular}{|l|c|c|c|c|c|c|}
\hline Parameter & Gas-proofed layer & Insulation layer & Leveling layer & Adjoining layer & Waterproof layer & Cumulative deviation \\
\hline Building6 & 17 & 230 & 29 & 18 & 25 & 14 \\
\hline Building7 & 18 & 222 & 27 & 16 & 23 & 2 \\
\hline Building8 & 18 & 231 & 23 & 17 & 24 & 8 \\
\hline Building9 & 18 & 222 & 28 & 18 & 23 & 4 \\
\hline Building10 & 14 & 220 & 28 & 16 & 25 & -2 \\
\hline Average value & 17 & 225 & 27 & 17 & 24 & $/$ \\
\hline Standard & 15 & 230 & 25 & 15 & 20 & 0 \\
\hline Permit deviation & \pm 3 & \pm 10 & \pm 5 & \pm 3 & \pm 5 & \pm 10 \\
\hline Real deviation & +2 & -5 & +2 & +2 & +4 & +5 \\
\hline
\end{tabular}

Seeing from table 1, during the implement of construction, although the quality of insulation layer and leveling layer in building one and building five emerged large deviations (show in grey panes of first column) and doesn't meet the rule, managers can find the problems at once after using evidence -science method, and correct these errors timely (show in grey panes of revise column). As result, the five buildings construction quality not only meet standard, but also the cumulative deviation of every building also reaches redesigned requirement. Therefore, the total passing rate of working procedure in five buildings is $100 \%$, all real deviations of five buildings also meet predetermined standards.

Then seeing the table 2, the all items which include gas-proofed layer, insulation layer, leveling layer, adjoining layer and waterproof layer in building six to ten also meet predetermined standard, 
and the average value and its corresponding real deviation of every building is eligible, but such problem which the cumulative deviation is not unqualified appears (show in grey pane of building six). It can be proved by the experimental result that although the deviation of every working procedure in every building is passed, but it is still possible that the cumulative deviation of every working procedure produces adverse effect to final engineering quality by traditional method. This is the real reason why the every working procedure and item as well as sub-engineering is qualified, while the whole engineering quality is unqualified in engineering practice.

Meanwhile, it can be found through comparing data in table one with in table two that the real deviations and cumulative deviations after using evidence-science method are less than the values by traditional method. So, the real experiment result proves the evidence-science method is valid if taking the evidence-science method to treat with residential engineering quality problems.

\section{Conclusion}

Aiming the quality problems in residential engineering, the research introduces the evidence-science on the basis of understanding and grasping evidence science principle. Then, the program to solve residential engineering quality based on evidence-science has been put forward together with the characteristics of residential engineering. At last, some following conclusions are obtained by a real engineering experiment.

(1) Comparing with traditional residential engineering quality management method, the evidence science management method can not only ensure the implement quality of every working procedure to meet predetermined requirement, but also eliminate the cumulative effect formed by deviation of every procedure to final engineering quality.

(2) In the management mode, the evidence-science method is a real dynamic management mode that can find unqualified points by instant-collected data rather than engineering finished data.

(3) After using the evidence-science management method, the real deviation and cumulative deviation tends to littler, this is benefit to improve the precision of engineering quality.

\section{Acknowledgement}

This study was supported by the national natural science foundation of China (Grant No. 71171081) and the natural science foundation of Beijing (Grant No. 9162014).

\section{References}

[1] Analysis on the residential engineering quality problems in China. http://ziliao.co188.com.

[2] J.A. Smith, J. Andrew: Evidence of Insufficient Quality of Reporting In Patent Landscapes in the Life Sciences. Nature Biotechnology Vol. 35 (2017), p. 210-214.

[3] G. Caniglia, J. Abson: Experiments and Evidence in Sustainability Science: A Typology. Journal of Cleaner Production Vol. 22 (2017), p. 121-125.

[4] A. Cheung, E. R. Slavin: Effective Secondary Science Programs: A Best-Evidence Synthesis. Journal of Research in Science Teaching Vol. 54 (2017), p. 58-81.

[5] K. Masada: A Study of Standardizing the Inspection Sheets for Evaluation of Quality of Building Maintenance. Journal of Technology and Design Vol. 23(2017), p. 607-611.

[6] A.Mohamed, R.W.Racha, A.B.Ahmed: Value Engineering Applications to Improve Value in Residential Projects. Canadian Society for Civil Engineering Vol. 21 (2015), p. 673-682. 